\title{
A Small Town Stroke
}

William Hoffman

(Fam Med. 2018;50(8):623-4.)

doi: 10.22454/FamMed.2018.420982

W atching a small town family doctor care for a patient in her final days compelled me to consider that something in our urban medical system may be missing.

I completed a stroke rotation in the neurology department of a large academic hospital on the East Coast during my third year of medical school. I saw patients flown in on helicopters, clots pulled out of their brains by a catheter threaded through their leg, and observed anticoagulation titrated by specialists armed with the latest vascular neurology literature. Some patients made miraculous recoveries while others succumbed despite a tremendous fight.

At the beginning of my family medicine rotation in a small hospital in rural Minnesota, I could not help but feel rather skeptical. I reflected on my assumptions about disparities in rural health care and how care here may compare to my experience in an urban academic hospital. My training centered on specialists caring for patients, and I assumed this was in the patient's best interest. How could one doctor know it all? Despite this perception, Dr Bob showed me that patients in a well supported rural hospital might have access to something that those in an urban medical center do not.

I met Mrs G when she came into the emergency department with weakness in her hand and slurred speech. She developed new onset atrial fibrillation and was throwing small clots into her brain. In her trendy green glasses and hospital gown, she beamed. She asked me what everyone asks in small communities: who did I know in town and to whom was I related? Her abounding laugh and quick wit were wholehearted and her energy infectious. It was hard to believe she was 88 . She teased that an overnight hospital stay would be disruptive to her busy social calendar but she acquiesced at the insistence of her longtime physician, Dr Bob. Later that evening, another clot profoundly infarcted her brain and left her with a severe aphasia. A woman known as a town socialite was left completely unable to speak.

I saw Mrs G in her hospital room the following morning, but I sensed a subtle absence as she offered me an uneven but genuine smile. She was gracious, and I held her hand for a few moments. She would eventually be able to nod yes or no, but her ability to speak would never return. The telemedicine neurologist said there was nothing left to offer and $\mathrm{Dr} \mathrm{Bob}$ discharged Mrs G home on hospice.

Mrs G's three daughters and son traveled to the hospital from Minneapolis and it was clear they had inherited her social genes. I mustered what I could from my neurology rotation to describe Mrs G's MRI results to these gregarious and impish Midwesterners. Dr Bob looked on and filled in as needed. They called him Bobby; the five grew up down the street from one another.

Dr Bob is a veteran family doctor of 40 years in this community. He cared for Mrs G since he finished residency in 1977, but their relationship began long before that. Mrs G was Dr Bob's neighbor when he was growing up in town. I came to realize the narrative between Mrs G and Dr Bob was similar for many in this community: Dr Bob cared for most people in town and delivered their kids and grandkids. He recently delivered a great-grandkid. An oldfashioned family doctor at heart, he seemed to engage the literature as closely as he did his patients.

After her first week of hospice, Mrs G's family called and asked if Dr Bob would see her at home. No stranger to a home visit, Dr Bob warmly agreed. Mrs G's striking decline troubled me when I accompanied Dr Bob into her home. Her daughters sat beside her, both holding a hand. She lay propped up on several pillows and her breaths were shallow. Though she appeared frail, she was affectionately dressed in a silky red robe and still wore those trendy green glasses. The Christmas tree near the window serenely lit the

From the Georgetown University School of Medicine, Washington, DC. 
room. Several black and white photos sat on a nearby nightstand. I admired a photo of Mrs G when she was no older than me.

"We're so glad you came, Bobby," said one of the daughters, her tears welling.

Dr Bob felt Mrs G's pulse. Despite her condition, there was a sense of peace and calm in the room. "Mom, Dr Bob is here." She smiled and adjusted some hair on her mother's forehead.

"How long do you think it will be Bobby?" She looked up, a tear now coming down her face.

"It's hard to say exactly, but I don't think it will be long." There was a pause. "She is comfortable, this is what she wanted."

Mrs G spent her final hours at home with her four children, recounting stories and reminiscing over pictures of her treasured life. Her doctor of 40 years stood by to guide her family in a central moment of their story. There was no helicopter, emergent MRI, or procedure; Dr Bob didn't have a stethoscope. He was caring for Mrs G by caring for her family. He cared for them in the context of knowing their history, their values, their mother, and her wishes. He was present as a familiar and principal member in the cast of Mrs G's life.
Mrs G passed away in her home down the street from the hospital where she was born more than 80 years before.

The therapeutic value of small town medicine is hard for me to put my finger on. While a large medical center may have offered state-of-theart technology and interventions, in some ways, Mrs G seemed better off in her rural community. Mrs G was lucky—she lived in a town with a well supported hospital and family physicians who spent their careers in the community. She did not want her final days to involve an emergency room, an internist, neurologist, and palliative specialist. She wanted Dr Bob to care for her until her death, and importantly, her local health care system enabled him to do that.

Dr Bob showed me the value of a town doctor who knows the local kids, neighbors, and story. This personal knowledge and enduring rapport helped his patients improve their diabetes with exercise or aid their smoking cessation. It was this relationship that helped his patients decide when to keep fighting illness or when to accept the inevitable. Embodying the duality of medicine as both a science and an art, Dr Bob employed evidence-based science while never overlooking the therapeutic value of a simple home visit. While patients in this community may not readily have access to the specialty therapies offered in an urban medical center, patients in a well supported rural hospital have access to a unique therapeutic relationship that improves their outcomes in ways not traditionally measured.

This story compelled me to consider that perhaps our focus on pushing medicine's boundaries has made it easy to overlook the urgent necessity to intimately understand someone's values in order to care for them. Perhaps the relationship between Dr Bob and Mrs G could be mirrored in a larger institution, but in a time when rural hospitals are closing, I hope we consider what may be lost.

CORRESPONDENCE: Address correspondence to Mr William Hoffman, Georgetown University School of Medicine, 2514 Tunlaw Rd NW \#302, Washington, DC 20007. wrh35@georgetown.edu. 